\title{
EL FACTOR CULTURAL EN LOS PROCESOS DE INTEGRACIÓN INTERNACIONAL. EL CASO DE LA UNIÓN EUROPEA
}

\section{THE CULTURAL FACTOR IN THE PROCESS OF INTERNATIONAL INTEGRATION. THE CASE OF THE EUROPEAN UNION}

Joaquín Sotelo González: Universidad Complutense de Madrid (España) joaquin.sotelo@ucm.es

\section{CURRÍCULUM VITAE}

Doctor en Ciencias de la Información (Periodismo) con Premio Extraordinario. Licenciado en Periodismo por la Facultad de Ciencias de la Información de la Universidad Complutense de Madrid (España). Es miembro de un Grupo de Investigación Validado Complutense y responsable principal de un proyecto de investigación competitivo. Ponente en varios Congresos nacionales e internacionales. Ha publicado numerosos artículos en libros y revistas científicas.

\section{RESUMEN}

La idea de la Europa comunitaria que se viene desarrollando desde mediados del siglo XX nació, esencialmente, como producto político-económico. La primera Comunidad Europea fue la Comunidad Europea del Carbón y del Acero. El asunto de la identidad cultural europea no está entre las consideraciones iniciales, pero está cobrando una importancia cada vez mayor en el proceso de integración continental. Se habla de multiculturalismo europeo y en el Tratado de Amsterdam se establece la defensa oficial de las culturas europeas. 


\title{
PALABRAS CLAVE
}

Unión Europea - Identidad cultural - Integración continental

\begin{abstract}
The idea of the European Community that has been developing since the midtwentieth century was born, essentially as political-economic product. The first European Community was the European Coal and Steel Community. The issue of European cultural identity is not among the initial considerations, but is gaining an increasing importance in the process of continental integration. There is talk of European multiculturalism and the Amsterdam Treaty establishing the official defense of European cultures.
\end{abstract}

\section{KEY WORDS}

European Union - Cultural identity - Continental Integration

\section{TEXTO}

La idea de la Europa comunitaria que se viene desarrollando desde mediados del siglo XX nació, esencialmente, como producto político-económico en un contexto internacional muy marcado por el belicismo de dos guerras mundiales prácticamente consecutivas y por la polarización mundial en dos grandes bloques de poder, liderados cada uno de ellos por Estados Unidos y la hoy extinta Unión Soviética. 
Resulta extremadamente difícil escindir lo económico de lo político en el proceso global de integración europea. De ahí lo arriesgado, si no imposible, de desgajar lo uno de lo otro, porque ambos se mezclan de manera indiferenciable.

La primera Comunidad Europea se fundó el 19 de marzo de 1951 y entró en vigor el 25 de julio de 1952: la Comunidad Europea del Carbón y del Acero (CECA), cuyo objetivo era poner bajo la dirección de una Alta Autoridad la producción siderúrgica de seis países europeos. Un proyecto de integración sectorial con marcado carácter supranacional, puesto que las decisiones de la Alta Autoridad eran directamente aplicables en los Estados que la componían: Bélgica, Países Bajos, Luxemburgo, Francia, República Federal de Alemania e Italia. Detrás de esta idea estaban dos de los denominados padres fundadores de la Comunidad Europea: Jean Monnet y Robert Schuman, afanados en reducir la posibilidad de nuevos conflictos armados por culpa de la siderurgia que tantas veces había enfrentado a Francia y a Alemania.

En los años siguientes a la constitución de la CECA, se debatió con profusión sobre las tres posibilidades de integración económica para Europa. El Reino Unido preconizaba la liberalización comercial sin cesión alguna de soberanía, es decir, una zona de libre comercio; Francia era partidaria, en un principio, de una integración sectorial, mientras que los países del Benelux, Italia y, finalmente, también Francia, defendían un proceso de integración económica completo. Se impuso esta última idea y, en junio de 1955, los ministros de la CECA propusieron su realización y un acuerdo sobre la producción de energía nuclear para usos pacíficos. El belga PaulHenri Spaak elaboró un informe sobre estos proyectos -conocido como informe Spaak- que fue aprobado en Venecia a finales de mayo de 1956. El desarrollo de los contenidos de aquel informe se plasmó en el Tratado constitutivo de la Comunidad Económica Europea (CEE) y en el de la Comunidad Europea de la Energía Atómica (CEEA o EURATOM), firmados ambos en Roma el 25 de marzo de 1957 bajo la 
denominación de Tratado de Roma, verdadera piedra fundacional de lo que hoy conocemos como Unión Europea.

Aquellas Comunidades Europeas surgidas a mediados del siglo XX comenzaron a interesar a otros países, que fueron solicitando acuerdos de asociación y adhesión. El primero de enero de 1973, se sumaron a los seis fundadores Irlanda, el Reino Unido y Dinamarca. En 1981, lo hizo Grecia. En 1986, España y Portugal. En 1995, Austria, Suecia y Finlandia. En 2004, República Checa, Estonia, Chipre, Letonia, Lituania, Hungría, Malta, Polonia, Eslovenia y Eslovaquia. Y en 2007, Bulgaria y Rumanía. Son los veintisiete Estados que hoy componen la actual Unión Europea, nombre contemporáneo de lo que comenzó siendo "las Comunidades Europeas".

Las consideraciones en torno a la naturaleza o dimensión cultural y civilizatoria del fenómeno comunitario no están en el origen del mismo, sino que son posteriores. Y ello a pesar de que en los proyectos de integración internacional parece conveniente prestar especial atención a tales consideraciones y no sólo a cuestiones políticas y económicas, dado que las oportunidades de supervivencia de una comunidad de naciones son directamente proporcionales a su grado de homogeneidad cultural, de manera que una comunidad culturalmente heterogénea tiene menos probabilidades de éxito, y viceversa.

El asunto de la identidad cultural europea está cobrando una importancia cada vez mayor en el proceso de integración continental.

A mediados de los años ochenta del pasado siglo, comenzó a extenderse por Europa cierto sentimiento de insatisfacción con un proceso de integración excesivamente -si no exclusivamente- marcado por lo económico. La utópica idea de Europa entendida como una comunidad de valores fue poco a poco alzando la voz como alternativa a 
la obsesión economicista de las naciones y de los grupos de interés. El Tratado de la Unión Europea, alumbrado en la cumbre mantenida por el Consejo Europeo en la ciudad holandesa de Maastricht a finales de 1991, incorporó en su articulado algunos elementos de política cultural (artículos 3(p) y 128) en los que los Estados firmantes instaban a la ejecución de acciones culturales en aras al reforzamiento de un sentimiento comunitario de participación de un patrimonio cultural y de valores compartido y a la contribución, al mismo tiempo, al florecimiento de las identidades culturales nacionales y regionales. Desde entonces, no han dejado de alzarse voces a favor de ese reforzamiento cultural europeo, de la unión por la cultura, de los valores culturales por encima de los políticos y económicos, idea que el propio Jean Monnet uno de los padres del moderno proyecto europeo de unificación- ya había consagrado célebremente en su día: "Si volviera a empezar, no empezaría por un mercado común. Empezaría por la cultura". Y Jacques Delors, años más tarde, completaba la idea de Monnet con una duda: “QQuién se enamora ya de un mercado común?". Es posible que la cultura sea un valor más seguro que el euro, que la política exterior y de seguridad común, que el espacio judicial único, que una Constitución Europea o que cualquier otra construcción política o económica expuesta siempre al rigor de los amenazantes factores exógenos e, incluso, endógenos.

Es cierto que se habla de multiculturalismo europeo, pero también de que esa circunstancia no empece hablar de un tronco común y compartido. Montesquieu dejó escrito en su Monarchie Universelle -y así lo reproduce José Antonio Jáuregui en su libro Europa: Tema y variaciones- que "Europa no es más que una nación compuesta de varias" , y el propio concepto de nación está lleno del de cultura. "La cultura europea -dice Jáuregui- es, en verdad, una síntesis formada multisecularmente a través de los siglos con elementos grecolatinos, judíos importados, pero adaptados a los moldes grecolatinos, a los que se han ido añadiendo en los siglos posteriores 
nuevas aportaciones, pero dentro de unas estructuras culturales que vertebran ordenadamente todo nuevo elemento añadido". El ejemplo que pone el profesor Jáuregui para significar la gran riqueza cultural de los europeos es el de la personalidad propia y única de cada una de las ciudades de nuestro continente, pero esas variaciones -puntualiza- no deben impedirnos ver los temas comunes.

El artículo 151 del Tratado de Ámsterdam consagra la defensa oficial de las culturas europeas y alude a una forma de "supracultura" compartida: "La Comunidad contribuirá al florecimiento de las culturas de los Estados miembros, dentro del respeto de su diversidad nacional y regional, poniendo de relieve al mismo tiempo el patrimonio cultural común".

Pero previo a cualquier teoría cultural ha de ser, evidentemente, aceptar el hecho de la existencia de una cultura, en este caso, de la cultura europea u occidental. En este sentido, José Ortega y Gasset distinguía a mediados del siglo XX entre una históricamente inexistente unidad europea y una siempre existente conciencia cultural europea: por una parte, Europa como cultura y, por otra, Europa como Estado. Ortega sustenta su tesis a partir de la idea de la convivencia de los pueblos europeos. Esa convivencia genera automáticamente una sociedad o sistema de usos europeos que indican la existencia de una opinión pública europea. Y esa opinión pública europea presiona en la forma de un poder público con carácter impositivo. Jesús J. Sebastián Lorente, en su artículo “La idea de Europa en el pensamiento político de Ortega y Gasset", recuerda alguno de los argumentos del filósofo español: "Nada más representativo y esclarecedor de esta cultura unitaria como el brote, durante el siglo XVII, de las literaturas nacionales, porque esta dispersión relativa de la cultura superior europea surgió, precisamente como efecto de un movimiento formalmente unitario y común europeo»". 
La "impresión" de Ortega es que el exaltado estado de vital particularismo en que viven los pueblos europeos -él habla a mediados del siglo XX, pero la idea, con matices, es igualmente válida hoy y tiene visos de seguir siéndolo- los lleva a cerrarse en sí mismos, a retraerse en sus peculiares tradiciones, a distanciarse de esa cultura común. Esta crítica circunstancia para la cultura europea va asociada a una pérdida de vitalidad y a un letargo de los pueblos. Y si éstos perciben ese problema, esa inseguridad, entonces vale como rigurosa y enérgica prueba de que existe una conciencia cultural europea. Ortega, en su línea de rehuir de ofrecer una definición de la cultura europea por determinados contenidos, sentencia que "la cultura europea es creación perpetua. No es una posada, sino un camino que obliga siempre a marchar".

El mero hecho de hablar de "choque/alianza de civilizaciones", de "diferencias culturales", de "brechas del conocimiento" y de muchas otras cláusulas similares, atestigua la existencia de diferentes núcleos culturales y de civilización en torno a los cuales se amalgaman los distintos pueblos de la Tierra. Y con ocasión de los atentados del 11 de septiembre de 2001 contra las Torres Gemelas de Nueva York, el debate se ha reabierto con mayor intensidad.

La civilización occidental ha sido históricamente la civilización europea, pero modernamente podríamos decir que es la civilización euroamericana o noratlántica. El término "occidental" -quizá más político e, incluso, militar, que cultural- alude a una parte de Europa, a Estados Unidos y Canadá y a áreas colonizadas en su día por los europeos como Australia y Nueva Zelanda.

El profesor norteamericano Samuel P. Huntington menciona en The clash of civilizations and remarking of world order (1997) (El choque de las civilizaciones y la reconfiguración del orden mundial) las principales señas de identidad de la única 
civilización designada con un referente geográfico -“occidental”-, y no con el nombre de un pueblo, de una religión o de una región particulares. En opinión de Huntington, la civilización occidental:

-Es la principal receptora de la herencia clásica: Filosofía y racionalismo griegos, derecho romano, latín y cristianismo.

-Encuentra en el catolicismo y en el protestantismo sus más importantes características.

-Carece de una lengua común, aunque bien lo pudo ser el latín en su día, pero propende al dominio de alguna: el francés en el siglo XVIII, el alemán en el XIX y el inglés en el XX y en la actualidad.

-Ha desarrollado singulares formas de libertad. En gran parte, derivadas de las rivalidades entre Iglesia y Estado y de la separación de poderes espiritual y temporal.

-Ha hecho de la ley un factor de extraordinaria importancia en la formación de su pensamiento y en sus formas de comportamiento. La ley es el principio rector del constitucionalismo y de la protección de los derechos humanos y su protagonismo ha sido mayor que en cualquier otra civilización.

-Es rica institucionalmente como consecuencia de su pluralismo social y de la presencia de cuerpos representativos de los miembros de sus sociedades.

-Basa su originalidad y su fuerza en el individuo. Ha asumido el individualismo a modo de confianza integral en la persona como elemento básico de la civilización. 
En definitiva, parece que disponemos de recursos para justificar la eventual existencia de un modelo de civilización europeo occidental o modelo ideológico dominante en una parte del continente, entendido éste según las delimitaciones geopolíticas oficiales actuales, al que subyacen elementos tales como la concepción individualista de la persona; el respeto por ésta debido a las legitimidades religiosa, política y económica; la idea de nación; la revolución científico-técnica moderna; el principio de la democracia y de su regla de la mayoría; el Estado de Derecho; el triunfo del capitalismo; el concepto romano de propiedad y la fuerza vinculante del contrato.

Puestos a buscar rasgos de especificidad de lo europeo, observamos que Europa occidental es efectivamente un espacio físico y mental singular de particulares características, entre las que destacan la sincronía en el tiempo y la generalización en el espacio de los grandes fenómenos histórico-culturales, comunes a todos los pueblos del continente: escolástica, renacimiento, barroco, ilustración...; la evolución continua de las corrientes artísticas y de los progresos científicos y tecnológicos; el acontecimiento de la novedosa edad científica y técnica moderna; la tendencia a la proyección mundial y cierta propensión a la originalidad de sus creaciones.

Huntington utiliza el criterio religioso para responder a la pregunta de qué parte de Europa pertenece a la civilización occidental y qué parte no. Los pueblos cristianos occidentales son los que integran esa cultura de la que quedan fuera los pueblos musulmanes y ortodoxos. El autor estadounidense marca una línea geográfica que delimita las distintas áreas en función de la influencia religiosa: "Empezando por el norte, corre a lo largo de lo que ahora son las fronteras entre Finlandia y Rusia y los Estados bálticos (Estonia, Letonia y Lituania) y Rusia, atraviesa Bielorrusia occidental, cruza Ucrania separando el oeste del este ortodoxo, pasa por Rumania entre Transilvania, con su población húngara católica, y el resto del país, y a través 
de la antigua Yugoslavia siguiendo la frontera que separa Eslovenia y Croacia de las demás repúblicas. En los Balcanes, por supuesto, esta línea coincide con la división histórica entre los imperios austrohúngaro y otomano". Nótese que la línea marcada por Huntington no coincide con la división estatal, ya que atraviesa el territorio de algunos Estados -como Bielorrusia, Ucrania o Rumania- para integrar la parte cristiana occidental de éstos en su cultura correspondiente.

A propósito de las apreciaciones de este profesor de la Universidad de Harvard, el 19 de octubre de 2002, la República de Irlanda ratificaba en referéndum el Tratado de Niza, desbloqueando así el desarrollo de este proyecto político de ampliación de la Unión Europea. Según las previsiones consagradas en aquel Tratado, a la Unión de 15 miembros se sumarían, en mayo de 2004, Estonia, Letonia, Lituania, Polonia, República Checa, Malta, Chipre, Eslovaquia, Hungría y Eslovenia (todos con notable componente cristiana occidental) y en 2007, Rumania y Bulgaria (de religión ortodoxa). Turquía (de religión musulmana) también es un futurible miembro, pero sin fecha concreta para la adhesión. Pues bien, Huntington considera que los acuerdos más factibles entre Estados son los de cooperación económica y que si esos Estados pertenecen a una única y misma civilización -caso de los candidatos que ingresaron en 2004- el éxito es más probable. El fundamento geográfico, generalmente regional, no sirve por sí solo para garantizar el buen fin de las organizaciones. Hace falta algo más.

Un caso especial es el de Grecia, el representante ortodoxo en los organismos internacionales. Religiosamente hablando, no forma parte de la civilización occidental, pero un rápido vistazo a su historia -indisolublemente unida a la occidental- sirve para desentrañar el secreto. Sobra insistir en la relación de la cuna de la cultura clásica y Occidente. No obstante, Huntington califica a este Estado de "problemático", tanto para la OTAN como para la Unión Europea. En notables 
ocasiones no se ha alineado con posturas "occidentales" (bloqueo a Macedonia, apoyo a los serbios en la guerra de la ex Yugoslavia...) y, en un futuro, según Huntington, su presencia en esos organismos se irá debilitando.

El éxito económico de la Unión Europea se explicaría entonces en clave "civilizatoria", así como el fracaso de otras organizaciones, como la Asociación de Naciones del Sudeste Asiático (ASEAN, en siglas inglesas), se explicaría por la heterogeneidad cultural de sus integrantes. La OTAN, compuesta por países occidentales con valores y principios filosóficos comunes, a excepción de Turquía, es otro ejemplo de éxito, como la Unión Europea Occidental (UEO). Sin embargo, la Organización para la Seguridad y la Cooperación en Europa (OSCE), integrada por países de distintas civilizaciones, se encuentra a menudo con importantes obstáculos a su desarrollo y a su funcionamiento.

Según Huntington, las organizaciones cuyos miembros comparten civilización precisan de un representante central aglutinante: Estados Unidos, en la OTAN, y el eje franco-alemán en la Unión Europea. La presencia y el reconocimiento de estos núcleos focales favorece el establecimiento de un orden siempre necesario.

Pero la pregunta clave en todo este debate es: ¿existe un sentimiento de "identidad europea" entre la ciudadanía del continente? A nuestro entender, la componente "identidad europea" pertenece aún únicamente al mundo de la reflexión intelectual y carece de la suficiente implantación en el imaginario individual y colectivo del conjunto de los europeos. El concepto de "nacionalidad" sigue profundamente arraigado en la conciencia de los ciudadanos de los países de la Unión Europea y es uno de los elementos de identificación personal fundamentales. No obstante, algunas naciones, entre las que destaca Italia, han incorporado la "europeidad" como 
elemento esencial de su identidad nacional, como característica de su "personalidad colectiva".

El politólogo estadounidense David Easton va aún más allá y distingue entre comunidad social y comunidad política y afirma que si bien esta segunda no precisa de los sentimientos para comenzar a funcionar, su aparición puede acabar generando una comunidad social. Los iniciales lazos instrumentales surgidos entre los miembros de una comunidad política por el mero hecho de compartir el trabajo político pueden acabar siendo los responsables de la aparición de lazos afectivos y sentimentales, sin necesidad de existencia previa de éstos como garantía de éxito de un proyecto político y/o económico.

En cualquier caso, Easton también considera muy importante que con el tiempo aparezca un sentimiento de comunidad social entre los miembros de la misma y que ese sentimiento actúe como fuente de apoyo al sistema cuando éste se vea amenazado por ciertas tensiones. No obstante, Easton matiza que los sistemas se pueden mantener durante tiempo con niveles de apoyo bajos. El verdadero peligro radica en el hecho de que los miembros se hagan conscientes de que una alternativa mejor es posible. En ese caso, los primeros en experimentar el descenso del apoyo serían las autoridades, luego, el régimen y, finalmente, la comunidad política en su conjunto.

El sistema político europeo está integrado por varios grupos y comunidades que, según Easton, en número elevado pueden aumentar las fuerzas centrífugas amenazantes para el sistema. Pero más conveniente que buscar apoyo por vía de homogeneización o asimilación forzada de grupos diversos es intentar lograrlo por vía de reconocimiento y respeto a la diversidad cultural de esos grupos y comunidades que, al mismo tiempo, tanto comparten. 
Comúnmente se acepta la idea de que manipular parámetros educativos y comunicativos del entorno puede contribuir a la creación de un mayor y muy deseable sentimiento de comunidad que, probablemente, no garantice por sí solo el éxito de un proyecto como el europeo, sino que deberá ir acompañado, además, de medidas tales como el incremento de la mutua correspondencia entre los miembros de la comunidad política, de la creación de expectativas de futuras recompensas por pertenecer a esa comunidad y de una eficaz socialización política que mueva a los individuos a interiorizar actitudes de apoyo hacia ella. 